\title{
3 The impact of life events on travel behaviour
}

\author{
Delphine Grandsart
}

\begin{abstract}
In the context of dealing with mobility poverty, it is relevant to consider how personal choices and (changes in) one's personal situation affect behaviour and, possibly, lead to behavioural change. A growing number of studies have explored and confirmed the impact of life events on travel behaviour. As most travel behaviour is habitual, it is a challenge to encourage people to consider other transport modes. For policy makers and transport service providers, it follows that life events or transition points can - and should - be considered as opportunities for triggering behavioural change, i.e. for promoting alternative transport options and nudging people towards using them.
\end{abstract}

\section{Life events in travel behaviour change theory: an overview}

Personal choices and (changes in) one's personal situation affect behaviour and may trigger behavioural change. In this chapter, we analyse how behaviour and behavioural change insights can be applied to the study of travel behaviour and travel behaviour change. First, we address a more theoretical framework and then we offer some case studies.

We can start with Adjei and Behrens (Adjei et al. 2012). In their review and synthesis of travel behaviour theories and experiments, they distinguish between four types of theories, depending on which questions they seek to answer:

- How behavioural choices are made (rational choice theory, prospect theory, habit formation theory, theory of interpersonal behaviour);

- What factors affect decision-making (theory of planned behaviour, theory of interpersonal behaviour, norm activation theory);

- When behavioural change occurs (habit formation theory, cognitive dissonance theory, stages of change model); and

- How people respond to behaviour change interventions (self-perception theory, goal setting theory). 
They conclude that "Rational Choice Theory" and "Theory of Planned Behavior" have so far been dominant as the underlying framework for travel behaviour analysis and experiments, even though other approaches notably prospect theory, habit formation theory, goal setting theory - are also receiving growing attention.

According to the theory of planned behaviour (Ajzen 1991), behaviour is the result of a conscious intention, shaped by people's attitudes, social norms and perceived behavioural control. However, the link between intention and actual behaviour appears to become much weaker in situations where habits take over. Habits can be defined as "a form of automaticity in responding that develops as people repeat actions in stable circumstances" (Verplanken et al. 2006, 91). The "habit discontinuity" hypothesis (Verplanken et al. 2008) states that (travel) habits or routines may become weakened - and hence, reconsidered - if important 'contextual discontinuities' or 'life events' occur, either in the individual's own life (e.g. moving home, changing jobs, marriage or divorce, acquiring a driving licence) and/ or in the wider societal (social, economic, spatial) context. Such events may be planned or unplanned, permanent or temporary. Verplanken et al. also suggest that context discontinuity may be coupled with 'self-activation' of personal views or attitudes, e.g. environmental consciousness, resulting in more sustainable travel behaviour.

In order to fully understand the importance of life events and their effect on people's (travel) behaviour, a long-term perspective can be useful. Until the end of the 20th century, travel behaviour research was mostly limited to the use of cross-sectional (instead of longitudinal) data and - with a few exceptions - little attention was paid to the effect of long-term decisions on travel behaviour (Lanzendorf 2003). To address these limitations, 'biographical research' has emerged as an interesting and promising approach to better understand travel behaviour and, more specifically, travel behaviour changes over the life course of individuals. The main advantage of such an approach is that it goes beyond the analysis of the current situation (i.e. which factors determine travel behaviour choices) and also takes into account the temporal dimension (i.e. how people's travel behaviour changes over time and how this can be linked to past experiences as well as future aspirations and plans).

The life course perspective in fact originated as early as in the 1960s, as an interdisciplinary and holistic approach to study the life histories or 'trajectories' of individuals and groups over time and the effects of personal but also social-historical context and conditions on behaviour. It has since then become a flourishing field of research. Within life course theory, a number of useful concepts have been developed that can also be applied to travel behaviour studies. Elder et al. define social pathways as structured trajectories of education and work, family and residences followed by individuals and groups that are shaped by historical forces and social institutions. Within such trajectories (i.e. sequences of roles and experiences), 
transitions (i.e. changes in state or role) open up a window of opportunity for behavioural change and may lead to a turning point - a substantial change in the direction of one's life, whether subjective or objective (Elder et al. 2003).

Drawing upon the life course approach, Lanzendorf (2003) introduced the term 'mobility biography' to refer to "the total of the longitudinal trajectories in the mobility domain". Lanzendorf considers that even though travel behaviour is to a large extent habitual - habit is understood as "the repeated performance of behaviour sequences by individuals" (Gärling and Axhausen 2003) - it may change over time. Sometimes, this is immediately and sometimes time lagged - as a result of specific events that involve major changes in the life course in either the 'lifestyle' domain (demographic, professional and leisure 'careers'), the 'accessibility' domain (locations of residence, workplace, shopping, leisure and other activities) and/or the 'mobility' domain (availability of modes: car ownership, public transport season ticket and actual activity and travel patterns) (Lanzendorf 2003).

In the conceptual model developed by Chatterjee et al. (2013), turning points in travel behaviour are triggered by contextual change (a life transition event or a change to the external environment). The reasoning is that life transition events can alter the roles people perform, their values and preferences, the resources available for travel and the context for travel (activity space). Intrinsic motivations, facilitating conditions in the external environment and personal history (past - positive or negative - experiences) also play a role as mediating factors (Chatterjee et al. 2013).

\section{Empirical studies confirming the impact of life events on travel behaviour}

Since 2003, a growing number of empirical studies have explored and confirmed the impact of life events on travel behaviour. A review of existing studies (Chatterjee and Scheiner 2015; Clark et al. 2014) shows that, indeed, the occurrence of important life events increases the likelihood of (lasting) changes to travel behaviour. Clark et al. also indicate that certain life events tend to cluster together, particularly in early adulthood, which increases their impact on travel behaviour (Clark et al. 2014). It should be noted that most studies conducted so far have been limited in scope, mainly because they have had to rely on relatively small sample sizes that may not be representative of the general population. In recent years, the increased availability of large-scale panel data sets has enabled researchers to track and uncover how travel behaviours evolve over time, for a large sample of test persons.

Two large-scale research projects are discussed in more detail below: the USEmobility survey (2011) and the Life Transitions and Travel Behaviour project in the UK (2012-2014). 


\section{The USEmobility survey}

In 2011, the "USEmobility" (Understanding Social behavior for Ecofriendly multimodal mobility) project investigated individual reasons that lie behind selecting a mode of transport. More specifically, USEmobility surveyed over 10,000 'swing users', i.e. citizens who had modified their mobility mix in the last five years, from six European countries (Austria, Belgium, Croatia, Germany, Hungary and Netherlands), about the reasons for their modal choice. USEmobility came up with a range of interesting new insights that are summarised below. ${ }^{1}$

The USEmobility survey first showed a lot of dynamism in people's choice of transport mode. Almost half of the people addressed in the survey were identified as so-called 'swing users', i.e. reported a change in their use of transport modes in the last five years. In metropolitan areas, a general increase in public transport use was registered, whereas in the rural areas, the change rather tended towards an increased use of private motorised transport.

$20 \%$ of the people involved in the research had decided to increase their use of public transport or to start using it for the first time. Within this group, the biggest segment (almost 1/3) consisted of 'complete changers' from motorised individual transport to public transport.

The highest dynamic was found for the travel purpose 'way to work'. In $2 / 3$ of the cases, the 'swing users' changed their travel behaviour 'step by step'; in $1 / 3$ of the cases, these changes took place 'overnight'. Swing users' behavioural patterns were also found to be much more multimodal and much more pragmatic than initially expected.

On average, $70 \%$ of the 'swing users' already used multimodal means of transport. It is also interesting to see that (in all countries) on average more than a quarter of swing users - the most important group - took a pragmatic point of view when choosing their mode of transport, i.e. they made different decisions according to the situation they were in and were the most dynamic in their behavioural patterns (Figure 3.1).

In general, pull-in factors (attractiveness of the transport offer) have a higher relevance than push-out factors (dissatisfaction with the means of transport used so far). We should also note how changes in one's personal situation are more relevant for a change towards public transport than for a change away from public transport. However, a decrease in public transport use is relatively often influenced by dissatisfaction (push-out).

For a continued use (including among swing users who have access to a car), public transport needs to be attractive (pull-in) in comparison to other means of transport. A new and surprising insight of the USEmobility project was how strongly changes in people's personal situation influence changes in their choice of means of transport. Indeed, habits and mobility routines play an important role in people's daily mobility.

Changes in one's personal situation (relocation, a new job, birth of children) give people an impulse to rethink their mobility routines, consider 


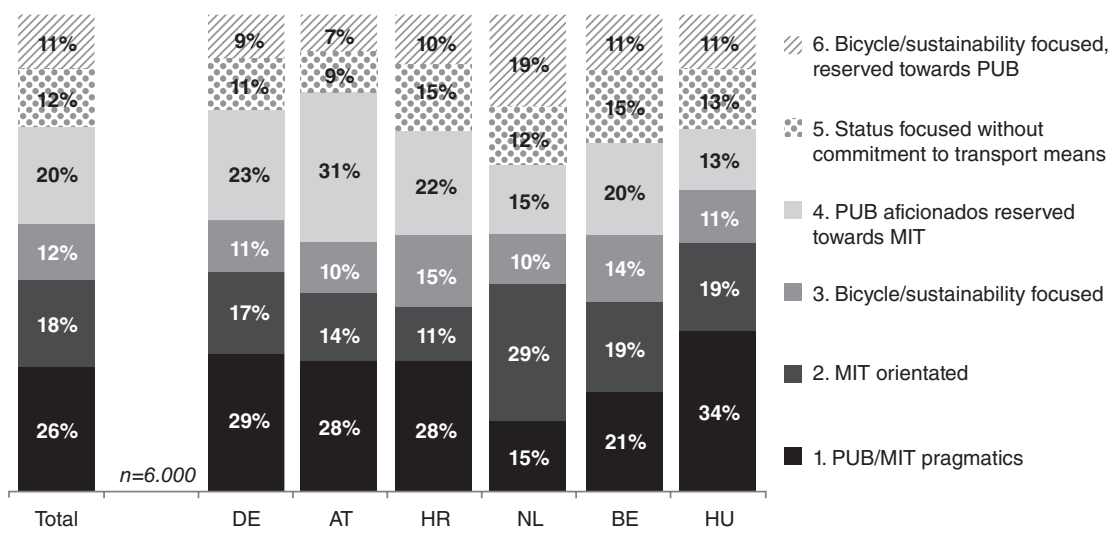

Figure 3.1 USEmobility segments of attitude by country.

Source: Knuth 2012.

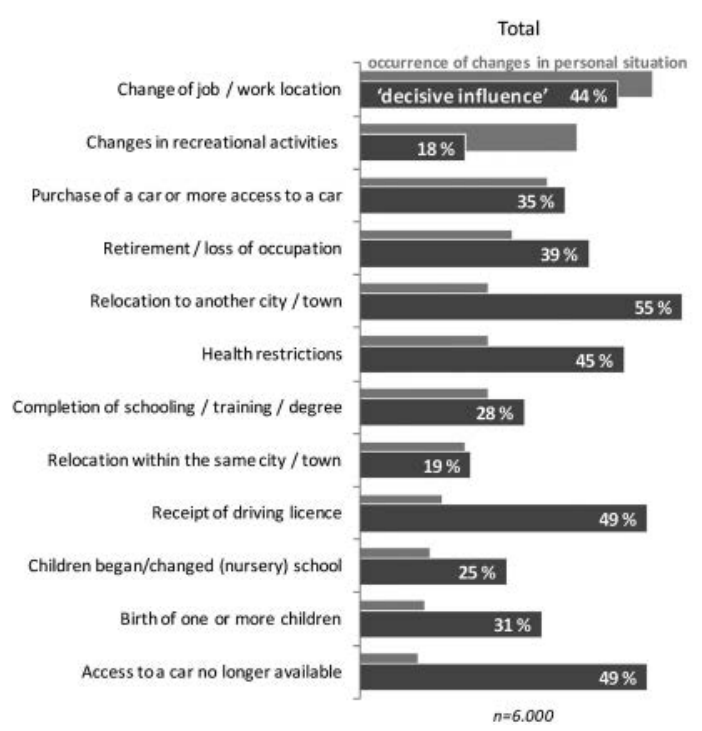

\begin{tabular}{|c|c|c|c|c|c|}
\hline $\mathrm{DE}$ & $\mathrm{AT}$ & $\mathrm{HR}$ & $\mathrm{NL}$ & $\mathrm{BE}$ & $\mathrm{HU}$ \\
\hline $43 \%$ & $42 \%$ & $27 \%$ & $47 \%$ & $50 \%$ & $50 \%$ \\
\hline $17 \%$ & $17 \%$ & $11 \%$ & $20 \%$ & $22 \%$ & $23 \%$ \\
\hline $33 \%$ & $30 \%$ & $24 \%$ & $43 \%$ & $39 \%$ & $46 \%$ \\
\hline $33 \%$ & $31 \%$ & $30 \%$ & $37 \%$ & $42 \%$ & $55 \%$ \\
\hline $67 \%$ & $60 \%$ & $39 \%$ & $55 \%$ & $45 \%$ & $61 \%$ \\
\hline $39 \%$ & $33 \%$ & $31 \%$ & $54 \%$ & $55 \%$ & $57 \%$ \\
\hline $30 \%$ & $21 \%$ & $19 \%$ & $30 \%$ & $44 \%$ & $32 \%$ \\
\hline $20 \%$ & $17 \%$ & $15 \%$ & $11 \%$ & $20 \%$ & $29 \%$ \\
\hline $51 \%$ & $52 \%$ & $28 \%$ & $64 \%$ & $70 \%$ & $35 \%$ \\
\hline $22 \%$ & $20 \%$ & $16 \%$ & $17 \%$ & $38 \%$ & $29 \%$ \\
\hline $36 \%$ & $32 \%$ & $21 \%$ & $26 \%$ & $36 \%$ & $40 \%$ \\
\hline $51 \%$ & $55 \%$ & $32 \%$ & $64 \%$ & $53 \%$ & $45 \%$ \\
\hline
\end{tabular}

Figure 3.2 Degree of influence of changes in one's personal/private situation on mobility decisions.

Source: Knuth 2012.

alternatives and change their behaviour. Over half of the survey participants stated that change in their personal situation was a central motivation for their reorientation (Figure 3.2).

A change of job or work location had, overall, the highest impact, followed (with considerable decrease in relevance) by relocation to another city 
or town (very relevant but not that common), increased availability of a car, retirement or loss of occupation and health restrictions (very relevant but not that common). Lost access to a car and obtaining a driving licence are highly relevant factors as well, but rather rare among swing users.

When people reconsider their mobility choices - due to a change in their personal situation and/or because new mobility alternatives become available - pull-in factors (attractiveness of a mode of transport, resulting in more frequent use) and push-out factors (dissatisfaction with a mode of transport, resulting in less frequent use) move into the spotlight. An overview of influencing factors is presented in Figure 3.3.

The USEmobility survey showed that 'hard' factors (reachability, cost, journey time, waiting time, number of transfers, frequency of connections) had the highest relevance in both the decision to use public transport and multimodal transport more often and, on the contrary, to quit public transport. For users to continue using public transport, their expectations regarding these 'hard' factors need to be fulfilled. If not, it can be expected that users will reduce or cease their use of public transport. Direct connections (without transfers) push increased use of public transport considerably.

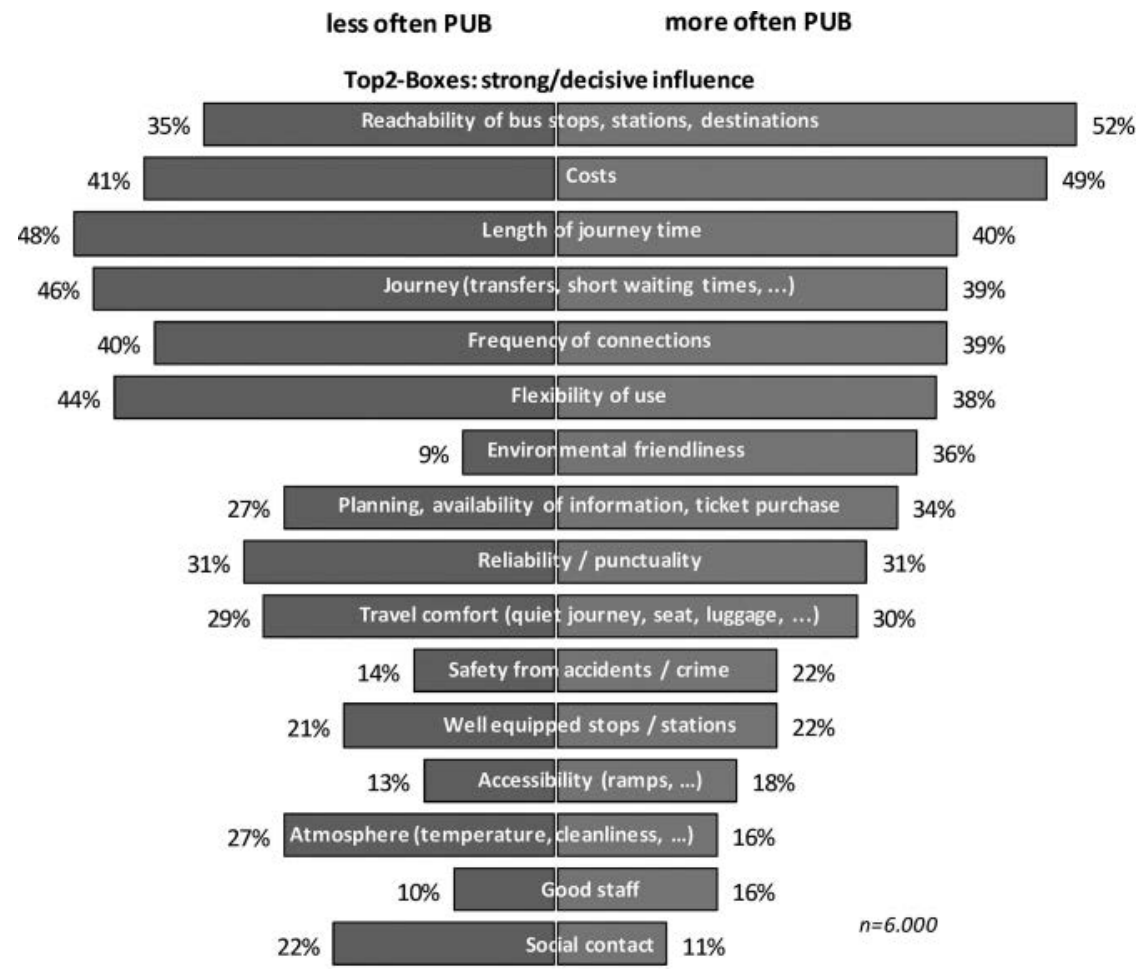

Figure 3.3 Influence of primary push-factors concerning public transport. Source: Knuth 2012. 
On the other hand, inadequate reachability of stops, stations and destinations, long waiting times, insufficient frequency of connections and crowding are the main factors that cause swing users to stop using public transport or use it less often. The influence of so-called 'soft' factors was less pronounced but still considerable. Among the soft factors, flexibility, planning effort, availability of information and environmental friendliness had the highest relevance followed by comfort of travel, atmosphere on the journey and staff. This to say that 'soft' factors can be regarded as complementary success factors that can contribute under certain circumstances to the increased use of public transport; however, they cannot completely substitute the 'hard' factors.

What we should keep in mind is how people facing a change in their personal situation are more open to reconsidering their mobility needs and solutions. Therefore, directly addressing people whose life circumstances have changed - for example, providing welcome or info packages to people who have relocated to another city or town or finished school or university; changed their job or retired; families who recently had a baby - opens up significant potential for influencing their modal choice (towards public transport and multimodality) at a relatively small cost.

And even if there is no change in someone's personal situation, the availability of information and knowledge about the existing (public transport, multimodal) offer is quite important, as most swing users base their decision to use public transport on their own experience or on information they have received from personal contacts (family, friends, acquaintances, colleagues). Relevant and comprehensive information should be provided to (potential) users, taking into account the needs of different target groups (e.g. young, elderly, disabled users, different travel purposes), e.g. by means of mobility trainings, awareness-raising campaigns.

\section{The life transitions and travel behaviour project}

The Life Transitions and Travel Behaviour project (2012-2014) was an 18-month research project conducted by the University of the West of England, the University of Essex and the Department for Transport. The research team made use of 'Understanding society' and British Household Panel Survey (BHPS) data to study how life transitions affect people's travel behaviour over time. The main results are summarised below.

A first important observation is that many people experience lifechanging events. In 2009-2010, the most common life events experienced in England were residential relocation (6.9\%), change of employer $(6.2 \%)$, entering employment from non-employment (5.1\%), lost employment $(3.3 \%)$, birth of a child (3.1\%) and gaining a driving licence (2.5\%) (Life Transitions and Behaviour Study 2014a).

The number of cars in a household is more prone to change at the time of life events: notably, starting and ending cohabitation, getting a driving 
licence, moving in and out of employment, birth of a child, changes in income, changing employer and residential relocation. Of course, apart from experiencing life events, other (more static) circumstances also play a role, such as household size, the presence of children or access to employment by public transport (Life Transitions and Behaviour Study 2014a).

Similarly, changes in commuting mode were found to be much more likely for those experiencing life events, notably changing job and moving home, because these have an obvious impact on the travel distance and transport options available. No less than $20 \%$ of the panel members involved in the study changed commuting mode. It should be noted here that car commuting appears to be far more stable than commuting by any other type of transport: on average, people commute six years by car and only three years by public transport, cycling or walking; and switches to car commuting are far more prevalent than switches to non-car and active commuting. Residential context (density, availability of public transport) also plays a role. Getting a driving licence makes a switch to car commuting more likely, whereas willingness to protect the environment increases the probability of switching from car to other commute modes. Interestingly, a change to car commuting is much more likely (30 times more likely) if the commuting distance increases above two miles, whereas a change to non-car commuting is more likely (but only nine times more likely) if the distance reduces below three miles. Also, environmental attitudes play a role: car commuters who are 'willing to act to protect the environment' are more likely to switch to non-car commuting (Life Transitions and Behaviour Study 2014b).

\section{Conclusion}

As most travel behaviour is habitual, it is a challenge to encourage people to consider other transport modes such as public transport, walking or cycling. For policy makers and transport service providers, it follows that life events or transition points can - and should - be considered as opportunities for triggering behavioural change, i.e. for promoting alternative transport options and nudging people towards using them. This could be achieved by means of interventions such as information and awareness raising campaigns, offering free public transport tickets targeted at people who have experienced a life-changing event. Young adults experience more change (move home, start a job, start a family, acquire a driving licence) and are hence an important group to target.

Pilot projects in this direction have already shown promising results. In Copenhagen, when a large sample of commuters who owned a car received a free public transport travel card, public transport use increased - but only among those who had moved home or changed workplace in the last three months (Thøgersen 2012). In the framework of the SEGMENT project (2013), welcome packs and cycle maps were sent to new residents of Utrecht - which 
led to a modal shift of $4 \%$ from car to cycling and public transport. In the West of England, travel advisors from TravelWest visited new residents at home to give them a Travel Information Pack and access to a range of free offers and promotions such as free bus tickets, cycle training and route planning assistance (Travelwest n.d.). Even though at this moment, more research is definitely needed on the efficacy of such interventions and how to measure their success (Chatterjee et al. 2015), we can conclude that taking life events into account should be a key element in any transport policy that aims to achieve travel behaviour change.

\section{Note}

1 For the full survey results, see USEmobility D3.6 - Factors influencing behavioural change towards eco-friendly multimodal mobility (Knuth 2012).

\section{References}

Adjei, Eric, and Roger Behrens. 2012. "Travel behaviour change theories and experiments: A review and synthesis." In 31st Southern African Transport Conference, Pretoria, 9-12 July 2012.

Ajzen, Icek. 1991. "The theory of planned behavior." In Organizational Behavior and Human Decision Processes, 50, no. 2: 179-211. https://doi. org/10.1016/0749-5978(91)90020-T.

Chatterjee, Kiron, and Ben Clark. 2015. "The facts are clear: Life events change travel behaviour. Policy-makers please take note." In Local Transport Today, 679: 18. http://eprints.uwe.ac.uk/26972. Accessed 20 January 2020.

Chatterjee, Kiron, and Joachim Scheiner. 2015. "Understanding changing travel behaviour over the life course: Contributions from biographical research." In 14th International Conference on Travel Behaviour Research, Windsor, UK, 19-23 July 2015. http://eprints.uwe.ac.uk/28177, Accessed 20 January 2020.

Chatterjee, Kiron, Henrietta Sherwin, Juliet Jain, Jo Christensen, and Steven Marsh. 2013. "A conceptual model to explain turning points in travel behaviour: Application to bicycle use." In Transportation Research Record, 2322 (1): 82-90. https://doi.org/10.3141/2322-09.

Clark, Ben, Kiron Chatterjee, Steve Melia, Gundi Knies, and Heather Laurie. 2014. "Life events and travel behaviour: Exploring the interrelationship using UK household longitudinal study data." In Transportation Research Record, 2413 (1): 54-64. https://doi.org/10.3141/2413-06.

Elder, Glen H., Monica Kirkpatrick Johnson, and Robert Crosnoe. 2003. "The emergence and development of life course theory." In Handbook of the Life Course, edited by Jeylan T. Mortimer and Michael J. Shanahan, 3-19. London: Springer.

Gärling, Tommy, and Kay W. Axhausen. 2003. "Introduction: Habitual travel choice.” In Transportation, 30: 1-11. https://doi.org/10.1023/A:1021230223001.

Knuth, Klaus-R. 2012. "Deliverable D3.6. Factors influencing behavioural change towards eco-friendly multimodal mobility." USEmobility Project. https://www. levego.hu/en/campaigns/usemobility/reports/survey/. Accessed 20 January 2020.

Lanzendorf, Martin. 2003. "Mobility biographies. A new perspective for understanding travel behaviour." In Anon. 10th International Conference on Travel 


\section{Delphine Grandsart}

Behaviour Research, Lucerne, 10th August 2003, 1-20. The International Association for Travel Behaviour Research.

Life Transitions and Travel Behaviour Study. 2014a. "Evidence summary 1 Household car ownership and life events." https://travelbehaviour.com/outputs1ttb/. Accessed 20/01/2020.

Life Transitions and Travel Behaviour Study. 2014b. "Evidence summary 2 - Drivers of change to commuting mode." https://travelbehaviour.com/outputs-lttb/. Accessed 20 January 2020.

"SEGmented Marketing for ENergy efficient Transport (SEGMENT)." n.d. https:// ec.europa.eu/energy/intelligent/projects/en/projects/segment. Accessed 20 January 2020.

Thøgersen, John. 2012. "The importance of timing for breaking commuters' car driving habits." In Collegium, 12: 130-140. https://helda.helsinki.fi/bitstream/ handle/10138/34227/12_08_thogersen.pdf?sequence=1. Accessed 20 January 2020.

Travelwest. n.d. "Moving home. New home, new start, new ways to travel..." https:// travelwest.info/movhome. Accessed 20 January 2020.

Van der Waerden, Peter, Harry Timmermans, and Aloys Borgers. 2003. "The influence of key events and critical incidents on transport mode choice switching behaviour: A descriptive analysis." Paper Presented at the 10th International Conference on Travel Behaviour Research, Lucerne, August 2003.

Verplanken, Bas, and Wendy Wood. 2006. "Interventions to break and create consumer habits.” In Journal of Public Policy and Marketing, 25 (1): 90-103. https:// doi.org/10.1509/jppm.25.1.90.

Verplanken, Bas, Ian Walker, Adrian Davis, and Michaela Jurasek. 2008. "Context change and travel mode choice: Combining the habit discontinuity and selfactivation hypotheses." In Journal of Environmental Psychology 28, no. 2: 121-127. https://doi.org/10.1016/j.jenvp.2007.10.005. 